\title{
Bridging the Gap: Development of the Entrepreneurial Philanthropy Alignment Model
}

\author{
Jos Rath $^{1} \&$ Theo Schuyt ${ }^{1}$ \\ ${ }^{1}$ Faculty of Social Sciences, VU University Amsterdam, The Netherlands \\ Correspondence: Jos Rath, Faculty of Social Sciences, VU University Amsterdam, The Netherlands. E-mail: \\ j.rath@rathgroup.com
}

Received: January 14, 2017 Accepted: February 3, 2017 Online Published: March 2, 2017

doi:10.5539/ijms.v9n2p1 URL: http://doi.org/10.5539/ijms.v9n2p1

\begin{abstract}
Partnerships are increasingly considered to have the potential to address societal problems that one single actor cannot solve. This paper rationalises the development of partnerships between entrepreneurs and non-profit organisations by the effects of its alignment. In organisations, the process of alignment focuses on the activities that management perform to achieve cohesive goals (e.g., finance, marketing, sales, human resources). Whereas in an entrepreneurial philanthropy partnership, the stage of alignment maturity addresses both how the opted societal change is in harmony with the entrepreneurial approach and how this approach can be in harmony with societal change. This approach is deemed crucial in understanding how the two partners can translate their views on leadership, strategy, and culture into opportunities that enhance their impact. Theoretical researches have provided foundations for identifying dimensions of the conceptual Entrepreneurial Philanthropy Alignment Model (EPAM) that might strengthen the impact of a partnership between an entrepreneur and a non-profit organisation.
\end{abstract}

Keywords: entrepreneurial philanthropy, partnership, alignment, model

\section{Introduction}

The importance of the concept of alignment has been acknowledged and documented since the late 1970's (McLean \& Soden, 1977). Over time, such focus has grown in importance as companies strive to link the continuously evolving technologies and businesses in light of dynamic organisational strategies (Luftman, 1996). Although alignment is often discussed in management literature, it is rarely explained in the dynamism of partnerships between entrepreneurs and non-profit organisations. The theory of alignment in this paper addresses the extent to which the corporate values of leadership, strategy, and culture can create an entrepreneurial philanthropic environment that facilitates the achievement of societal change. Alignment maturity can be defined as the degree to which the individual members of the strategic partnership are motivated to behave according to the defined partnership goals (Beer, 2009). To illustrate the strategic relevance of this effect, it might be helpful to use alignment as a measure of the partnership goals. Alignment is expected to require planning, a willingness to reassess and make adjustments regularly, and a workforce that feels involved and responsible for the partnership achieving its goals. These outcomes can be the result of an intense partnership dialogue, or sometimes more simply, the result of joint skills, visions, and gains. The findings of the present research may help the partners to remove barriers impeding cooperation, and thereby increases the performance of individuals, processes, and the partnership organisation as a whole to create a greater philanthropic impact.

\section{Research Context}

As a form of philanthropy, entrepreneurial philanthropy is not new. However, the concept is evolving. The 21st century is likely to be an age of accelerated strategic partnerships between non-profit organisations and entrepreneurial philanthropists (Shaw et al., 2013). A working definition of strategic partnership has been posed by Brinkerhoff (2002, p. 22) as "a dynamic relationship among diverse actors, based on mutually agreed objectives, pursued through a shared understanding of the most rational division of labour based on the respective comparative advantages of each partner". So-called philanthropreneurs have established these strategic partnerships with non-profit organisations to define ambitions to achieve greater impact on a scale proportionate to wicked problems in society (Rath \& Schuyt, 2014). These partnerships bring expertise from the business sector in their approaches to problem solving, operating models, and theories of change. Rather than 
focusing on the traditional grant-giver or grantee relationship, the entrepreneur takes a more dynamic and hands-on approach by providing capacity building and developing management expertise in partnership with the non-profit organisation they support (Frumkin, 2003). These strategic partnerships are emerging because entrepreneurs are seeking new forms of engagement with their (local) communities and are increasingly re-examining their philanthropic practices. Matching a non-profit's vision with the skills and funding of an entrepreneur can be a powerful combination. Even so, entrepreneurs must acquire legitimacy to be regarded by others in the field of philanthropy. It has been suggested that various forms of capital are heavily intertwined in the process of entrepreneurial philanthropy. Importantly, this approach is not just about supporting the most effective and trustworthy non-profit organisation, but rather it is a partnership that constantly seeks alignment to build intended impact from informed understanding. The definition of "Entrepreneurial Philanthropy" used in this paper is as follows:

The search of entrepreneurs (\& their companies) to create an aligned partnership with a non-profit organisation for a greater impact of philanthropy, contributing business principles such as tailored investment, human network, knowledge transfer, and/or time capacity, therefore acquiring economic, and/or symbolic returns (Rath \& Schuyt, 2015).

Frequently, when entrepreneurs and directors of non-profit organisations wish to build a partnership to realise a significant impact on civil society, a certain lack of alignment can appear as a type of "Tower of Babel" confusion (Moody, 2008). This issue may affect the mutual expectations on the envisioned partnership, which only partially comes to fruition. In the worst case, the project, despite everyone's good intentions, does not commence at all. Theoretical research into the strategic planning process of companies and non-profit organisations has yielded insight into the business aspects that contribute during the alignment process aimed at establishing partnerships. Those aspects have been subdivided into the domains of: leadership, strategy, and culture (Vicere, 2010). Using Key Performance Indicators (KPIs) (Kaplan \& Norton, 1992; Parmenter, 2010), 25 theoretical determinants in these three domains have been implicated in building and organising a strategic partnership. Following qualitative research among five entrepreneurs or directors and seven directors of non-profit organisations, 16 determinants (Figure 1) were found to be significant and therefore selected for further research (Rath \& Schuyt, 2015).

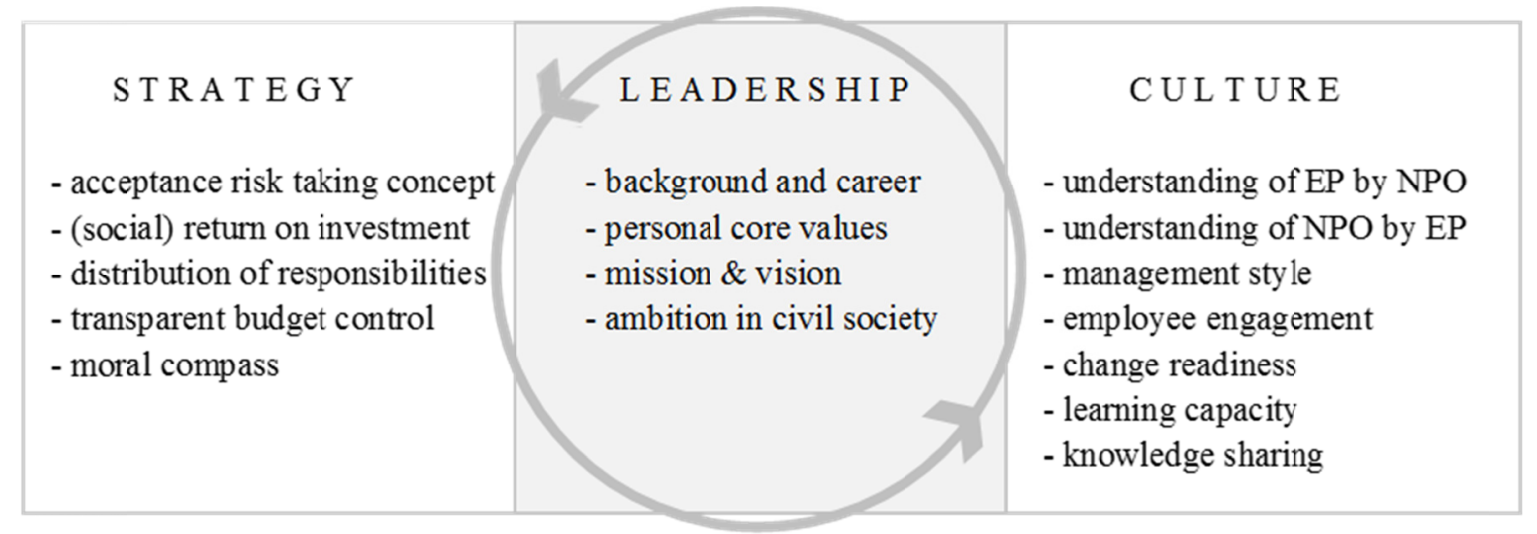

Figure 1. Theoretical framework of entrepreneurial philanthropy alignment

The hypothesis posed in this paper is that the degree of alignment in Leadership, Strategy and Culture will affect the partnership between anentrepreneurial philanthropist and the director of a non-profit organisation. The American term "alignment" relates to the negotiation process (synchronisation) between organisations to realise effective partnerships. The importance of alignment is increasingly recognised and has been empirically found to have positive effects on organisational partnership performance (Delery \& Doty, 1996). Alignment may refer to two aspects. First, it can relate to "the act of aligning" or the process of negotiation, convergence, connection, and realising commitment. Secondly, alignment may refer to "the state of being aligned", which refers to the state of optimum convergence, connection, and commitment. In this paper, alignment is defined as the sense of the alignment process between the direct partners building towards a potential partnership (Lachotzki \& Noteboom, 2005). Forming and maintaining a partnership is a complex process complicated by member confusion about how to describe their endeavour, clarify their purposes, organise their activities, and establish 
operating agreements. A partnership that has managed to remove alignment blockades, often by successful interventions, finds itself "aligned", meaning that the domains of leadership, strategy, and culture are linked and connected with those expected to make a contribution (Van Dinten, 2013). During this process, both parties aim to achieve their objectives to demonstrate their justification within the partnership (with alignment as the key condition).

Alignment in entrepreneurial philanthropy refers to the convergence process between entrepreneurs (and their companies) and the management of non-profit organisations, as well as to the problem of matching business principles offered by entrepreneurs with the requirements of the non-profits. The theoretical exploration of alignment might lead to a roadmap that both further develops the convergence process, and details the effectiveness of the methods and techniques that can be used to achieve a state of alignment. This concept has been regarded as a means towards achieving alignment, which implies a mutually beneficial partnership (MacKechnie, 2010). The added value produced by such a partnership is expressed as a more effective and efficient approach to philanthropic issues with both partners actively striving to contribute to the discovery and realisation of a greater impact in society.

\section{Theoretical Exploration of Alignment in Partnerships}

In recent years, the competitive advantage of corporate organisational performance that contributes positively to business partnerships has received attention both in international management theory and in practice (Holtbrügge, 2004). Partnerships are increasingly understood as pieces of a larger puzzle, rather than as comprehensive, stand-alone approaches. In addition, the interest in partnerships between businesses and non-profit organisations is increasing and becoming more strategically important (Austin, 2000). However, non-profits do not always feel comfortable with an entrepreneurial approach, which may lead to confusion, and unfortunately resulting in the suspension or cancellation of partnerships (Moody, 2008). Therefore, it is important that each party synchronises competitive strategies with existing strategies for engagement to build and sustain partnerships. In addition, entrepreneurial philanthropy that aims to establish alignment maturity in the domains of leadership, strategy, and culture are more capable of producing a mutual profitable partnership performance (Rath \& Schuyt, 2015).

While these domains are understood, and generally considered as common sense, the difficulties lies in trying to operationalise and implement this approach to create effective partnership skills, which are crucial in all disciplines. Thus, the theoretical model proposed in this paper is based on the development of alignment maturity in partnerships and aims to further understand behavioural and social dynamics in this context. Alignment in partnerships is widely believed to improve synergistically of performance. However, achieving alignment remains an on-going challenge and concern for management and the biggest challenge for executives is to ensure that the organisation makes the correct choices (Papp, 1995).

The aim of developing an Entrepreneurial Philanthropy Alignment Model (EPAM) is to make a contribution to define what determinants within the domains matters most to alignment and to additionally create a roadmap for achieving the purposes of both partners. This goal requires an effective planning process, a willingness to reassess and make adjustments regularly, and a workforce that feels involved and responsible for the organisation achieving its partnership (Chorn, 1991). The question that drives alignment in an entrepreneurial philanthropy partnership is not easily answered. Therefore, it is logical to more closely explore the three selected domains of the model through established research theories.

\subsection{Domain Leadership: The Linking Path}

Lachotzki \& Noteboom (2005). Managing Strategic Alignment Through Corporate Dialogue. John Wiley and Sons. Key insight: Leadership primarily contributes to partnerships'success and their structural gains.

Within a societal context, an organisation aims to achieve their ambitious objective using an influence relationship among leaders and followers who intend real changes that reflect their mutual purposes (Rost, 1991). From a dynamic perspective, there is generally a healthy form of tension between embracing the personal core values and the ability to realise the formulated ambitions. The leader of an organisation typically wants to continuously measure and manage the alignment between the elected strategy and its execution. Leadership occurs within the context of core values, it guides and facilitates to make a positive difference, and contributes to a larger good. In practice, however, motivational sessions, visits, or reviews have been insufficient means to engender a high degree of understanding of leadership within the organisation and to ensure change is supported and carried out. From a more ideological perspective, leadership entails issues that envision a certain impact on society. As there are no easy solutions, these issues often result in a public debate due to the worldview or values in question. These factors complicate the organisation's ambitions, where the societal context is reflected in factions or interest groups (e.g., social, cultural, or environmental). Leadership, after all, is handling issues set in 
a social matrix of heterogeneous institutions and their relationship with transparency and accountability. Leadership instruments such as policy, chain and network management, and ambiguity management are crucial tools in the process of alignment. By focusing on what leaders believe and value, and then positively building on this understanding, the potential for impact is far more reaching than when leadership is approached as a problem-solving activity.

Management beyond the control strategy implementation model has shifted the focus from structured safeguards to driven interaction. This shift in focus has been achieved by leading with a strategic "pull" and an operational "push". This approach requires a permanent "corporate dialogue" between all levels of the organisation and it is in this way that the strategic convergence of the organisation can be constantly measured and managed. This dialogue can only be implemented in a structured and consistent manner using specially designed communication infrastructure, also known as the Executive Dialogue Centre (EDC). This EDC is an Internet portal that has been developed to function as a virtual office to facilitate leadership interaction between management, employees, and other stakeholders. The portal also allows management to steer their decision-making process and simultaneously manage the processes of the company.

In addition, this tool allows alignment to be managed by developing delineated perspectives in which employees can participate and grow in an environment of accountability and freedom. Within this scenario, the leadership process is defined by four key factors, which are: clear intention, robust objectives, effective interaction, and resource support. These factors may help define the alignment problems of an organisation and can, for those organisations that desire this outcome, locate and evaluate the obstacles in the alignment process and continuously create results that exceed the expectations of stakeholders.

\subsection{Domain Strategy: The Guiding Path}

Kaplan \& Norton (2006). Alignment: Using the Balanced Scorecard to Create Corporate Synergies. Boston: Harvard Business School Publishing Corp. Key insight: Strategic alignment is quantifiable.

The strategic alignment process discussed in this paper is based on the Balanced Scorecard (Kaplan \& Norton, 1992). The objective of the balance scorecard is to connect everyone and everything in organisations with the elected alignment strategy. Within this approach, the management must align the goals and gains correctly to engender a high degree of commitment among their employees to reach their goals and gains. Additionally, the organisation should be motivated and trained to support the careful execution of the strategy elected. Both the envisioned impact and outcome should be clearly formulated and synchronised appropriately to not only move towards achieving relation synergies but also financial synergies and synergies in internal processes.

Executing such strategies requires a certain degree of versatility to continuously implement small and large changes. A strategy that generates enthusiasm within an organisation but is unable to shift from obsolete methods and structures, for example, is not likely to push any boundaries. Importantly, the successful execution of such a strategy requires the full commitment of a number of key actors within the organisation to realise individual projects and plans. The tension between the responsibility to maintain daily operational results and the adaptive capacity of the organisation is a dilemma. A mature strategy development and implementation in the alignment process requires continuous action to be taken. Eight indicators allow this strategy to be measured and managed:

1) The value proposition of the organisation;

2) Management and shareholder/investor alignment;

3) Head office and support services alignment;

4) Head office and business unit alignment;

5) Business unit and support services alignment;

6) Business unit and customer alignment;

7) Business unit and supplier and alliance partner alignment;

8) Alignment between support services of business units and those of the head office.

According to Kaplan \& Norton (2006), the alignment process may be hindered if one of these indicators is not met or is only partially satisfied. Ultimately, alignment is quantifiable but the quality of the measurements is primarily determined by the degree of convergence and commitment.

\subsection{Domain Culture: The Driving Path}

Van Riel (2012). The Alignment Factor: Leveraging the Power of Total Shareholder Support. London: Routledge. Key insight: Alignment of cultures entails building and maintaining a (mutually beneficial) partnership. 
From a business perspective governed by the interests of an organisation, its economic principles, and engineering abilities, alignment refers to building a long-term relationship with both the internal and external stakeholders an organisation. Network organisation is paramount and this involves scanning the environment from an internal orientation perspective, which links prevalent corporate world paradigms. There are three fundamental traits of corporate culture embedded in building and maintaining alignment. Building alignment starts with collecting relevant information (e.g., on public opinion, behaviour of employees) followed by supporting information on the proposed course of action, and subsequently a demonstration of successes and ensuring accountability. These three characteristics consist of both external and internal cultural components.

Building sustainable, mutual relationships with stakeholders commences with a collection of relevant information. Internally, this relates to knowledge of all characteristics of the organisation identity and the extent to which employees support and promote the strategy in their daily activities. From an external point of view, knowledge on public opinion must be collected including the organisation's reputation and specific branch issues. Within that process, management may choose to take a negotiation or confrontation stance. A negotiation strategy typically employs techniques such as consultation and building consensus. Confrontation, however, is about "mirroring" (e.g., influencing newspaper articles) and "power play" (e.g., taking legal action). All available data should be shared with management and constitutes input for the decision-making process that may lead to the desired alignment. Ultimately, the success of an organisation is determined by its level of alignment.

Organisations with alignment maturity are more successful because they build "mutually rewarding partnerships" both internally and externally. In this way, an organisation's image throughout a successful process goes from reputation as a tool to alignment as an organisational goal. Consequently, communication professionals have increasingly focused on building alignment. This trend supports the stance that organisations should produce results and organise, channel, process, and make use of any criticism from stakeholders. In addition, organisations must ensure that both parties are aware of each other's arguments and facilitate a shared culture. In alignment, it is not about winning or losing a discussion but about gaining respect, which in turn, creates a negotiation position.

\subsection{Partnership: The Result}

Austin (2000). Strategic Collaboration Between Nonprofits and Businesses. Nonprofit and Voluntary Sector Quarterly, 29(1), 69-97. http://dx.doi.org/10.1177/089976400773746346 Key insight: A partnership goes through stages: 1) Philanthropic, 2) Transactional, and 3) Integrative.

The growing complexity and magnitude of problems in civil society exceed the capacities of individual organisations to address them. As a result, non-profits are becoming increasingly aware of the need to diversify their resources and the importance of expanding their partnerships to include businesses. Entrepreneurs who recognise the opportunities and benefits of working with non-profit organisations aim to move beyond traditional philanthropic activities and towards partnerships that are more entrepreneurial and business-like. In this approach, the two sectors co-create new values for themselves or others and the strategic question becomes how they can establish greater value for organisations, individuals, and society. Likewise, a growing number of businesses are aware that their customers and shareholders expect corporations to act responsibly by providing support for important community issues and events.

As a result, non-profits have to be able to find a common ground that links the societal needs they believe to be important with the business interests of entrepreneurs and this challenge can be addressed through strategic partnerships. According to Austin (2000), successful partnerships built on principles of collaboration enables the participating organisations to move from the traditional philanthropic relationship to a more integrative relationship. The integrative relationship, unlike the philanthropic, is more equitable. In this arrangement, the two organisations work on issues they both believe are important, make recognised equity investments for a mutual return, and agree to share resources. In addition, each party works to make the relationship a dynamic one that encourages an active learning experience.

As an outcome of this research, Austin discovered a practical set of seven practices present within the strongest strategic partnerships:

1) Clarity of purpose;

2) Connection with purpose and people (i.e., an emotional connection with actual social cause that creates a psychological force, interpersonal chemistry between the partners);

3) Congruency of mission, strategy, and value; 
4) Creation of value (if both partners are asking themselves how they can create value for their partner, collaboration is most valuable);

5) Communication inside and outside (to ensure that everyone understands why the partnership is important for attaining the mission, and that stakeholders are also informed of the important alliance);

6) Continual learning (continually trying to discover how to create more value and how each party can learn how to partner together);

7) Commitment to the partnership (not seen as official deals but as long term relationships based on a fundamentally deep commitment through good and bad times).

The description of the human element in these practices is interesting and indicates partnerships between entrepreneurs and non-profits are not simply a question of applying standard operating procedures for collaboration. In addition, these findings demonstrate how alignment helps to establish and manage strategic partnerships that are effective and mutually beneficial.

\section{Theoretical Framework}

Based on further exploration of the theoretical framework of Entrepreneurial Philanthropy Alignment (Figure 1), we expect a crucial consideration when selecting a determinant is its theoretical relevance for addressing an aspect of the phenomenon in question. Therefore, it follows that valuable predictor determinants have action, that is, they move from observation to observation and can create adifference between or among other determinants. Theoretical exploration of the concept of alignment along the domains leadership, strategy, and culture provided input to address the determinants of the theoretical framework, which were based on the Key Performance Indicators (Kaplan \& Norton, 1992; Parmenter, 2010).

\subsection{Leadership}

Evidence has demonstrated that leadership might be an important linking principle in the alignment process to create a partnership (Lachotzki \& Noteboom, 2005). In addition, it has been suggested a small subset of leadership skills closely correlates with the success of the partnership, particularly among the frontline thought leaders of entrepreneurial philanthropy. The personal core values of these people are viewed as the decision guidelines of how the corporate dialogue consciously or unconsciously creates partnerships (Cardona, 2000). Therefore, it is necessary to understand, develop, and mobilise these leadership capabilities in ways to be both profitable and responsive to societal challenges. Leadership in entrepreneurial philanthropy partnerships is not only about developing and communicating a shared mission and vision, but is also about sustaining commitment to achieve impact in (civil) society. The process of importance is trust in effective problem solving when information is gathered, analysed, and considered. This problem solving implies a relatively difficult issue to achieve alignment with, yet it might be a key input into decision making for considerable partnership issues (e.g., ambitions in civil society) and daily challenges (e.g., how to increase knowledge sharing within the team) (Brookes, 2006). Leaders who are strongly results-orientated tend to emphasise the importance of efficiency and productivity with inspirational leadership as the ultimate advantage. However, there is a need for different types of skills, such as a generalised ability to sustain conflict within a partnership and the development of experience in non-structured relationships based on continually emerging processes. Seeking different perspectives are expected to be important to grasp changes in civil society, encourage staff to contribute ideas that could improve performance, accurately differentiate between strategic and minor issues, and assign the appropriate weight to the various partnership concerns (Stanzo et al., 2011). Although partnerships are defined by the motivation of both partners, they are expected to be the result of the core values, mission, and vision, and the ambition to realise impact in society. Therefore, it might be prudent to understand and practice behaviour patterns and values of leadership that encourage the alignment process of the desired partnership.

\subsection{Strategy}

For developing a partnership strategy, leadership is viewed as the impetus because it offers unique opportunities such as financial resources, skills, or networks. Within the process of alignment, strategy theories may suffer from an instrumental emphasis and certain assumptions about mutuality in decision making among partners, democratic control, and accountability among stakeholders (Austin, 2000). Importantly, the partnership strategy might guide each partner to further develop the most relevant mission and vision to derive a maximum impact (Iyer, 2003). The more common the entrepreneurial philanthropy partnership purpose is to each partners' strategy, the more aligned the relationship is likely to be, including following the same guiding path to achieve shared goals (Googins \& Rochlin, 2000). Following this approach, developing an exit strategy is a commonly overlooked consideration of a partnership, yet it might play a key role in determining its strategic direction. In 
the process that occurs within three chronological stages of partnerships (formation, implementation, outcomes), an exit strategy should examine the in-depth motivations behind the partnership, and is therefore the integral part of the process when terminating a long- or short-term partnership (Warner \& Sullivan, 2004). In addition, the emergence of risk taking means that outcomes-based funding is advancing the alignment of funding with shared goals. The distribution of responsibilities as a result of and required by the partnership is an area of interest considered important both in theory and in practice, particularly when measuring the assessment of the partnership or the "social return on investment". It is also useful to examine the implementation of risk taking concepts, the distribution of power, and the performance measurement to identify how strong these factors are and whether they support the alignment of the partnership (Kaplan \& Norton, 2006). The outcomes of entrepreneurial philanthropy partnerships can be measured at three levels: direct impact on the issue and its stakeholders; impact on building capacity, knowledge, or reputational capital that can attract new resources; and influence on social policy or system change (Selsky \& Parker, 2005). This approach requires that non-profits also show entrepreneurial instinct to measure the results that can be used to contribute to the mission of the partnership.

\subsection{Culture}

A partnership's culture comprises of a set of intangibles, which are the shared beliefs, values, and assumptions about how both partners think, behave, and react. This culture can be viewed as a self-reinforcing web of individual and partnership management styles in a collective (organisation, community, etc.) for producing the outcomes of a shared concept and commitment (Drath et al., 2008). Previous research has demonstrated that organisational culture can positively influence organisational performance by motivating staff and shaping employee behaviours toward specified goals (Daft, 2007). Culture can enable a partnership to constantly adapt to changing conditions and quickly react to dynamic environments. In addition, setting goals and expectations early in the partnership process establish both sides of the alliance guideposts to regularly evaluate the alignment of the partnership. Therefore, a partnership may provide an opportunity for one partner to internalise the skills of the other and thus improve its position both within and without the alliance. The joint process of developing a shared mind-set and communicate about it is therefore essential (Van Riel, 2012). Effective internal employee communications, which convey a clear description of how to reach strategic alignment, ensures the employee effort is focused in the right direction and can create an adaptability culture that emphasises responsiveness and flexibility. Communicating clearly, asking the right questions, and engaging in continuous learning might be the driver behind generating high employee engagement, which can therefore be expected to outperform. Alignment of entrepreneurial philanthropy goals, values, and commitment provides evidence that each of the partners must invest time and resources to build the partnership in a way that reflects the needs, capacities, and resources of the other. An effective partnership culture is crucial for building trust, finding common ground, and creating multiple solutions that allow the most appropriate ideas to formulate (Asif \& Palus, 2014). In a partnership dialogue, both partners might learn to ask more and better questions, pay more careful attention (also to the general public), and explore respective perspectives. Ultimately, success is governed by the ability to develop new knowledge assets that may create core partnership competences.

\section{Entrepreneurial PhilanthropyAlignment Model}

There are recognized benefits and advantages to develop entrepreneurial philanthropy partnerships in which both partners have common ground and a purpose of interest to all parties. However, establishing effective partnerships takes time, and it is expected to be important to create the right framework from the beginning and review the process of alignment on an ongoing basis to measure its success or failure (Beer, 2009). Partnerships might imply a shared leadership among respected individuals who are recognized and empowered by their own organisations and trusted by partners to build consensus and resolve conflicts (Cobb et al., 1998). In addition a common understanding of the strategy and culture of partner organisations must exist, including a clear understanding of individual members' roles and responsibilities regarding the division of labour.

Management practices and resources are also expected to achieve partnership goals and complement the intended purpose of the partnership (McNeil, 1995). Specifically, the partners must demonstrate accountability for the output or outcome and take ownership for the delivery of the objectives and targets for which they are responsible, and share these with internal and external stakeholders. Fundamentally, in the partnership process, alignment involves the optimal matching of decision problem characteristics with a known approach strategy.

Based on the theoretical exploration of alignmentin partnerships, a conceptual Entrepreneurial Philanthropy Alignment Model (Figure 2) has been developed, which examines the experiences of creating a strategic fit to develop collaboration over time. The model is built upon the assumption that a partnership's ability to achieve its 
goals is a function of the degree of congruence between the three domains discussed previously in this paper. The model expresses the extent to which an entrepreneur (and their company) matches its resources and capabilities with the opportunities in the non-profit organisation. Therefore building theories of alignment is demanding to any research effort related to entrepreneurial philanthropy. Critical in any research process is developing and testing the right questions to determine whether the theoretically predicted determinants are achieved. Therefore, the choice for alignment determines the analytical methods that can be used. The methodology used in this paper provides a means of framing the decision problem so the roadmap to alignment, or their lack of, can be defined. Maturity and the ability to manage the development, implementation and maintenance of partnerships on various levels, depends on how the various determinants within the domain have been identified as important to the partnership, and affects the performance of the activities in civil society. Intended partners using only a few determinants can have a low alignment but might find ways to adjust their partnership. Those using no aspects at all should stop their intention to create a partnership. Partnerships that adopt many determinants are likely to achieve alignment and have the potential to be successful. The model will be quantitatively tested in the Netherlands among entrepreneurs or directors of their companies, and the directors of non-profit organisations, who haveexperience in creating a partnership.

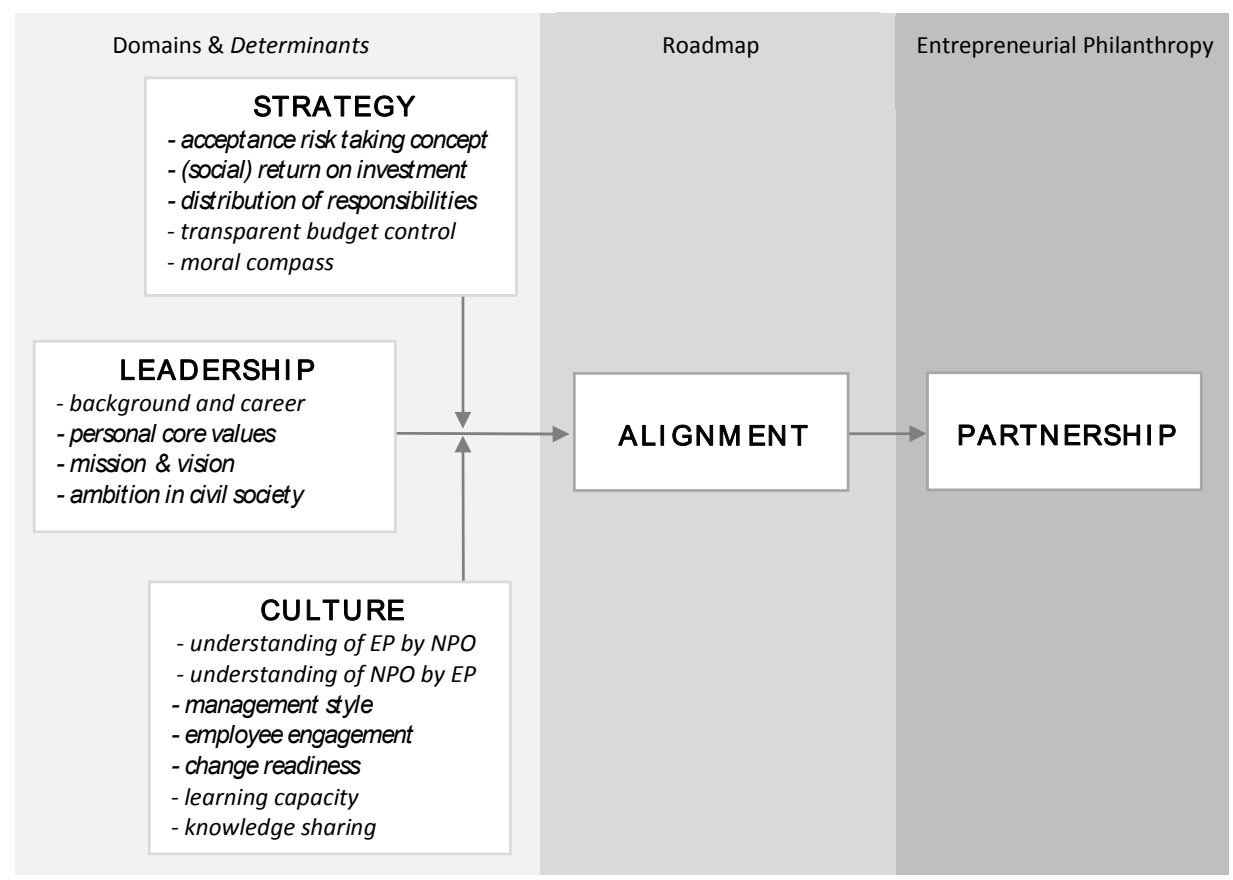

Figure 2. Conceptual Entrepreneurial Philanthropy Alignment Model (EPAM)

\section{Research Questions}

The primary research question addresses in this research is:

Does the EPAM-model (Figure 2) explains whether a partnership between an entrepreneur (and their company) and the director of a nonprofit will be established?

The secondary research questions are:

a. To what extent does the degree of alignment determine the creation of a partnership between an entrepreneur and the director of a nonprofit?

b. To what extent does a partnership between an entrepreneur and a director of a non-profit organisation develops through leadership?

c. To what extent is strategy a guiding principle for the partnership between an entrepreneur and a director of a nonprofit, and is culture its supercharger?

\section{Hypothesis}

A number of research hypotheses are derived that guide the subsequent analyses. These are an extension of the 
studies performed by Rath \& Schuyt (2014, 2015), all of whom have researched the extent to which companies are engaged in entrepreneurial philanthropy partnerships.

1) There is a positive relationship between leadership and the degree of alignment in an entrepreneurial philanthropy partnership.

2) Alignment in entrepreneurial philanthropy varies according to which extent the strategy is guiding the partnership.

3) Alignment in entrepreneurial philanthropy varies according to which extent the culture is super charging the partnership.

4) There is a positive relationship between personal core values, mission/vision and ambitions in civil society of both partners.

5) There is a positive relationship between acceptance of the risk taking concept, the social return of investment and the distributions of responsibilities of both partners.

6) There is a positive relationship between the management style, employee engagement and change readiness of both partners.

7) The effect of the independent variable alignment explains the success of the entrepreneurial philanthropy partnership.

\section{Methodology}

Previous chapters have presented a gap in the entrepreneurial philanthropy knowledge base, identified the absence of a means to identify and measure the factors that causes alignment in partnerships, and proposed a theoretical model, EPAM, to address this gap. To test the EPAM-model in this investigation, a brief number of questions were distributed in the business section of the quantitative 2016 "Giving in the Netherlands Panel Survey" of VU University. The questionnaire included six questions about the relative importance of each of the domains within the EPAM-model to establish an entrepreneurial philanthropy partnership, and may providean indication of its predicting values.

Unlike quantitative research, qualitative research places greater emphasis on the context to understand the nature of the phenomenon being investigated as it is an appropriate strategy for gaining insight into situations for which further explanation is needed. This is essential to the descriptive stage of theory building through observation and classification, therefore further research with in-depth interviewswas the chosen method because this approach provides a rich source of information and can generate adequate data from a small group to determine the motivation for the partnership decisions made. As Bell (2010) demonstrated, qualitative research is distinguished as a contextual approach in which data are gathered in natural real-life settings from a subjective perspective to explore unusual, and as yet unseen, depths within phenomena of interest. The purpose of the interviews is to provide the ability to investigate different viewpoints of the targeted philanthropic partners and gain an insight into the workings of the areas of leadership, strategy, and culture for the alignment process, which can ultimately contribute to knowledge about the creation of a partnership. This qualitative research is fundamentally interpretive and emphasises context to understand the nature of the phenomenon. By using a semi-structured interview protocol, combined with more exploratory in-depth questions, a dialogue with the interviewees can be created (Legard, Keegan, \& Ward, 2003). The groundwork for these questions are based on defined determinants and can be expanded to include others when the interview gives reason to do so. The results of this study aim to be valued in a theoretical type of generalisation because the results should be applicable to a larger group of interested entrepreneurs and nonprofit organisations.

Finally, through purposive sampling based on the selection of information-rich cases through maximum-variation sampling, a dozen directors of non-profits will be selected and interviewed. After the questioning, they will be asked to supply (via chain referral sampling) the name of a company director they actually have a partnership with. The ultimate goal of this study is to conduct approximately $2 \times 10$ interviews. For each target group aquestionnaire has been developed. The interview process is, to some extent, flexible, while ensuring that all questions about the determinants are discussed. These interviews will be recorded and analysed in subsequent work, so the interview data can relate effectively to the EPAM model.

\section{Conclusion and Research Agenda}

This study has indicated leadership is connecting the domains strategy and culture to accomplish alignmentin the partnership between an entrepreneur and a non-profit, which may create a roadmap how to achieve the desired societal change by maximising alignment enablers and minimising inhibitors. In combination with previous 
findings it is expected that alignment may be beneficial for an effective partnership because it has been established that weak alignment can cause confusion or conflict. The presented alignment gap in the development of philanthropy partnerships might also be addressed by the proposed conceptual EPAM-model.

Additionally, the existence of vibrant entrepreneurial philanthropy partnerships is increasingly being viewed not as a luxury, but as a necessity in many places across the globe. The intent is to discover the drivers of alignment in partnerships and provide a method to assist entrepreneurs and non-profit organisations in this dynamic environment to create a greater impact of philanthropy. This journey will continue with both a quantitative and a qualitative research study of the EPAM-model conducted in The Netherlands.

\section{References}

Asif, V., \& Palus, C. J. (2014). Leadership Strategies for Societal Impact. A White Paper. Greensboro: Center for Creative Leadership.

Austin, J. E. (2000). Strategic Collaboration between Nonprofits and Businesses. Nonprofit and Voluntary Sector Quarterly, 29(1), 69-97. http://dx.doi.org/10.1177/089976400773746346

Beer, M. (2009). High Commitment High Performance: How to Build a Resilient Organization for Sustained Advantage. Hoboken: John Wiley \& Sons.

Bell, J. (2010). Doing Your Research Project. Columbus: McGraw-Hill Education.

Brinkerhoff, J. M. (2002). Government-nonprofit partnership: a defining framework. Public Administration and Development, 22(1), 19-30. http://dx.doi.org/10.1002/pad.203.

Brookes, S. (2006). Out with the Old, In with the New: Why Excellent Public Leadership Makes a Difference to Partnership Working. International Journal of Leadership in Public Services, 2(1), 52-64. http://dx.doi.org/10.1108/17479886200600010

Cardona, P. (2000). Transcendental leadership. The Leadership \& Organization Development Journal, 21(4), 201-207. http://dx.doi.org/10.1108/01437730010335445

Chorn, N. H. (1991). The "Alignment" Theory: Creating Strategic Fit. Management Decision, 29(1), 20-24. http://dx.doi.org/10.1108/EUM0000000000066

Cobb, J. C., Samuels, C. J., \& Sexton, M. W. (1998). Alignment and Strategic Change: a challenge for marketing and human resources. Leadership \& Organization Development Journal, 19(1), 32-43. http://dx.doi.org/10.1108/01437739810368811

Daft, R. L. (2013). Organization Theory and Design. South-Western: Cengage Learning.

Delery, J., \& Doty, D. H. (1996). Modes of theorizing in strategic human resource management: tests of universalistic, contingency, and configurational performance predictors. Academic Management Journal, 39(4), 802-835. http://dx.doi.org/10.2307/256713

Drath, W. H., McCauley, C., Palus, C. J., Van Velsor, E., O’Connor, P. M. G., \& McGuire, J. B. (2008). Direction, alignment, commitment: Toward a more integrative ontology of leadership. Leadership Quarterly, 19(6), 635-653. http://dx.doi.org/10.1016/j.leaqua.2008.09.003

$\begin{array}{llllll}\text { Frumkin, } & \text { P. (2003). Inside Venture Philanthropy. Society, 40(4), }\end{array}$ http://dx.doi.org/10.1007/s12115-003-1013-0

Googins, B. K., \& Rochlin, S. A. (2000). Creating the Partnership Society: Understanding the Rhetoric and Reality of Cross Sector Partnerships. Business and Society Review, 105(1), 127-144. http://dx.doi.org/10.1111/0045-3609.00068

Holtbrügge, D. (2004). Management of international strategic business cooperation: Situational conditions, performance criteria, and success factors. Thunderbird International Business Review, 46(3), 255-274. http://dx.doi.org/10.1002/tie.20008

Iyer, E. (2003). Theory of alliances: Partnership and partner characteristics. Journal of Nonprofit and Public Sector Marketing, 11(1), 41-57. http://dx.doi.org/10.1300/J054v11n01_04

Kaplan, R. S., \& Norton, D. P. (1992). The Balanced Scorecard-Measuresthat Drive Performance. Harvard Business Review, 1992(01), 71-79. PMID: 10119714

Kaplan, R. S., \& Norton, D. P. (2006). Alignment: Using the Balanced Scorecard to Create Corporate Synergies. Boston: Harvard Business School Publishing Corporation. 
Lachotzki, F., \& Noteboom, R. (2005). Managing Strategic Alignment Through Corporate Dialogue. Hoboken: John Wiley \& Sons.

Legard, R., Keegan, J., \& Ward, K. (2003). In-depth Interviews. In J. Richie \& J. Lewis (Eds.), Qualitative Research Practice (pp. 139-168). London: Sage.

Luftman, J. (1996). Competing in the Information Age: Practical Applications of the Strategic Alignment Model. New York: Oxford University Press.

MacKechnie, B. (2010). Achieving Strategic Alignment: How to Harness its Power to Exceed your Organizational Goals. Washington: Double Bee Publishing.

McLean, E., \& Soden, J. (1977). Strategic Planning for MIS. Hoboken, New Jersey: John Wiley \& Sons.

McNeil, R. D. (1995). Partners in the Marketplace: A New Model for Business-Civic Leadership. National Civic Review, 84(3), 248-255. http://dx.doi.org/10.1002/ncr.4100840310

Moody, M. (2008). Building a Culture: The Construction and Evolution of Venture Philanthropy as a New Organizational Field. Non Profit and Voluntary Sector Quarterly, 37(2), 324-352. http://dx.doi.org/10.1177/0899764007310419

Papp, R. (1995). Determinants of Strategically Aligned Organizations: A Multi-industry, Multi-perspective Analysis. Hoboken, New Jersey, Stevens Institute of Technology,

Parmenter, D. (2010). Key performance Indicators: Developing, Implementing, and Using Winning KPI's. Hoboken: John Wiley \& Sons.

Rath, J. H., \& Schuyt, T. N. M. (2014). Entrepreneurial Philanthropy: an Exploratory Review. Journal of Wealth Management, 17(3), 35-46. http://dx.doi.org/10.3905/jwm.2014.17.3.035

Rath, J. H., \& Schuyt, T. N. M. (2015). Entrepreneurial Philanthropy Meet with Non-Profits: In Search of Alignment. Journal of Economic Behavior and Organization, 3(4), 55-64. http://dx.doi.org/10.11648/j.ijebo.20150304.11

Rath, J. H., \& Schuyt, T. N. M. (2015). From Philanthropy to Partnerships: Testing a Theoretical Framework of Entrepreneurial Philanthropy Alignment. Journal of Service Science and Management, 8(3), 425-442. http://dx.doi.org 10.4236/jssm.2015.83044

Rost, J. C. (1991). Leadership for the Twenty-First Century. New York: Praeger.

Selsky, J. W., \& Parker, B. (2005). Cross-Sector Partnerships to Address Social Issues: Challenges to Theory and Practice. Journal of Management, 31(6), 1-25. http://dx.doi.org/10.1007/s10551-011-0776-2

Shaw, E., Gordon, J., Harvey, C., \& Maclean, M. (2013). Exploring contemporary entrepreneurial philanthropy. International Small Business Journal, 31(5), 580-599. http://dx.doi.org/10.1177/0266242611429164

Stanzo, K. L., Myran, S., \& Clayton, J. K. (2011). Building bridges between knowledge and practice: A university-school district leadership preparation program partnership. Journal of Educational Administration, 49(3), 292-312.

Van Dinten, R. (2013). Blokkades in het strategische alignmentproces: Een instrumentarium om tot inzicht in de $k$ waliteit en het belang van het strategische alignment te komen. Breukelen: Nyenrode Business Press.

Van Riel, C. B. M. (2012). The Alignment Factor: Leveraging the Power of Total Shareholder Support. London, UK: Routledge.

Vicere, A. A. (2010). The Real Legacy of Leadership: Aligning Rhetoric with Reality. In M. Goldsmith, J. Baldoni, \& S. McArthur (Eds.), The Handbook of Leadership. New York: AMA.

Warner, M., \& Sullivan, R. (2004). Putting partnerships to work. Sheffield, UK: Greenleaf.

\section{Copyrights}

Copyright for this article is retained by the author, with first publication rights granted to the journal.

This is an open-access article distributed under the terms and conditions of the Creative Commons Attribution license (http://creativecommons.org/licenses/by/4.0/). 